\title{
A CONTRIBUIÇÃO DA EDUCAÇÃO FÍSICA ESCOLAR PARA UM ESTILO DE VIDA ATIVO
}

\author{
Rodrigo de Rosso Krug* \\ Moane Marchesan $^{* *}$ \\ Marco Aurélio Acosta***
}

\section{Resumo}

Esta investigação objetivou analisar as contribuições da Educação Física Escolar para a adoção de um estilo de vida ativo pelos alunos da $3^{a}$ Série do Ensino Médio de uma Escola Estadual em Cruz Alta-RS. Caracterizou-se por ser de abordagem qualitativa fenomenológica sob a forma de estudo de caso. O instrumento utilizado para a coleta de informações foi uma entrevista semiestruturada, analisada através da análise de conteúdo. Participaram 20 alunos da $3^{\text {a }}$ Série do Ensino Médio de uma Escola Estadual de Cruz Alta- RS, sendo 10 do gênero masculino e 10 do feminino, com idades entre 17 e 19 anos. Pela análise das informações obtidas concluímos que a Educação Física Escolar contribuiu para a adoção de um estilo de vida ativo pela grande maioria dos alunos estudados.

Palavras-chave: Educação Física. Estilo de vida. Atividade Física. Saúde.

\section{THE CONTRIBUTION OF PHYSICAL EDUCATION SCHOOL FOR AN ACTIVE LIFESTYLE}

\begin{abstract}
This research aimed to analyze the contributions of school physical education to adopt an active lifestyle for students in 3rd series HighPublic School in the city of Cruz Alta-RS. Was characterized by being a qualitative approach with a phenomenological approach and the form of case study. The instrument used for data collection was a semi structured interview, interpretation was content analyzed. Participants were 20 schoolchildren of the 3rd series of HighPublic School of the city of Cruz Alta-RS, 10 were male and 10 female, aged between 17 and 19 years. For the analysis of information to conclude that school physical education contributed to the adoption of an active lifestyle for the vast majority of students studied.
\end{abstract}

Keywords: Physical Education. Lifestyle. Physical activities. Health.

\footnotetext{
${ }^{*}$ Mestre em Ciências do Movimento Humano, Licenciado em Educação Física pela Universidade de Cruz Alta.

** Mestre em Educação Física, Doutoranda em Educação Física da Universidade Federal de Santa Catarina, Fisioterapeuta e Licenciada pela Universidade de Cruz Alta.

*** Doutor em Ciências do Movimento Humano, Professor do Centro de Educação Física e Desportos e do Curso de Pós-Graduação em Ciências Sociais da Universidade Federal de Santa Maria.
} 


\section{Introdução}

O estilo de vida ativo é um dos maiores determinantes da saúde das pessoas, sendo fundamental na redução da mortalidade por todas as causas. Pode ser definido como um conjunto de ações baseados na prática regular de atividades físicas (AF) em prol da saúde do individuo (NAHAS, 2006).

Apesar do vasto conhecimento sobre os benefícios que um estilo de vida ativo proporciona ao organismo (WHO, 2002), a inatividade física está aumentando em todo o mundo, sendo que $60 \%$ das pessoas não atingem a recomendação mínima de 150 minutos semanais de AF moderada (OPAS, 2003).

Hallal et al. (2003) salientam que a promoção da AF deve começar nos primeiros anos de vida, pois evidências mostram que adolescentes que seguem as recomendações mínimas de prática de AF e que tem uma boa alimentação têm menores riscos de ter doenças na vida adulta e possuem maiores tendências de continuarem ativos durante toda a vida.

Neste sentido, o professor de Educação Física (EF), que além de ser um educador é um profissional de saúde, deve informar aos seus alunos, bem como as demais pessoas, sobre os benefícios de um estilo de vida ativo, principalmente na prevenção e na reabilitação de doenças. Além disso, o professor de EF deve ser o mediador da prática de AF, tanto dentro como fora da escola, tendo importante papel em relação à promoção da saúde, educação e prevenção de doenças, contribuindo assim para hábitos de vida mais saudáveis (KRUG et al., 2009b). Sabe-se que a Educação Física Escolar (EFE) tem vários propósitos, e que esta, deve, com base no conhecimento corporal popular e de suas variadas formas de expressão cultural, almejar que o aluno possua um conhecimento organizado, crítico e autônomo sobre a cultura humana de movimento (DAÓLIO, 1996), porém, neste estudo será enfocada a Educação para a Saúde, com o propósito de mostrar para os alunos a importância de se adotar um estilo de vida ativo.

Com isso, Ferreira (2001), enfatiza que a EFE deve despertar nos alunos o gosto e o prazer pela AF para que possam adotar um estilo de vida ativo. Devide (1996) acrescenta que a EFE deve levar os alunos a se exercitar, desenvolvendo, além dos conhecimentos necessários à prática, a consciência de sua importância e de seus benefícios para o seu bemestar, além de possibilitar que identifiquem os fatores que os impedem de praticar $\mathrm{AF}$ regularmente.

Quadros e Krebs (1998) relatam que apesar dos alunos em qualquer idade escolar dificilmente apresentarem problemas crônicos degenerativos, pouco tem se investido em sua 
formação, no que se refere a um estilo de vida ativo. Desta mesma forma, Guedes e Guedes (1995), destacam que mesmo que estes problemas ainda não tenham se manifestado nesta idade, não significa que estes alunos estejam imunes a fatores de risco que no futuro possam provocar doenças, ou que não devam receber informações sobre os benefícios de um estilo de vida ativo desde a infância e adolescência, pois a preservação de sua saúde repercutirá por toda vida.

Assim, objetivou-se neste estudo analisar as contribuições da EFE para a adoção de um estilo de vida ativo pelos alunos da $3{ }^{\text {a }}$ Série do Ensino Médio de uma Escola Estadual em Cruz Alta-RS.

\section{Procedimentos Metodológicos}

Esta pesquisa caracterizou-se como qualitativa fenomenológica, do tipo estudo de caso, privilegiando a consciência do sujeito e entendendo a realidade social como uma construção humana (TRIVIÑOS, 1987). Koogan e Larousse (1990) explicam que a fenomenologia é o estudo descritivo de um conjunto de fenômenos e o estudo de caso, de acordo com Goode e Hatt (1968), mostra o interesse naquilo que ele tem de único, de particular, mesmo que posteriormente fiquem evidentes certas semelhanças com outras pesquisas.

Para a coleta de dados utilizou-se a entrevista semiestruturada com as seguintes questões: Você gosta de EF? Por quê?; Você faz EF atualmente e/ou fez durante todo Ensino Médio? Por quê? Como foram essas aulas?; Como foram suas aulas de EF no Ensino Fundamental?; Você participou de equipes esportivas escolares? Por quê? Qual? Em que época?; Você realiza regularmente AF fora da escola? Qual e com que frequência?; Por qual motivo?; Alguma vez o professor de EF lhe incentivou/influenciou a fazer AF regularmente? Como e por quê?; A EFE contribuiu para a adoção de um estilo de vida ativo?; Você acha importante a disciplina de EF no currículo escolar? Por quê?

Foram entrevistados 20 alunos (16 a 19 anos), sendo 10 do gênero masculino e 10 do feminino. A escolha desta amostra foi intencional aleatória, justificando-se por estes já terem passado por todos os segmentos escolares com aulas de EF. Todos concordaram em participar do estudo e assinaram o termo de consentimento livre esclarecido. Após a aplicação das entrevistas foi utilizada a análise de conteúdo (BARDIN, 1977) para a interpretação dos dados. 


\section{Resultados}

Os resultados serão apresentados em duas partes, onde na primeira estão os dados relativos à prática de atividade física na escola e na segunda os dados sobre a prática de atividade física fora da escola.

\section{A prática da EF na escola}

\section{O gosto dos alunos pelas aulas de EF na escola.}

Dezenove alunos $(1 ; 2 ; 3 ; 4 ; 5 ; 6 ; 7 ; 8 ; 9 ; 10 ; 11 ; 12 ; 14 ; 15 ; 16 ; 17 ; 18 ; 19 ; 20)$ declararam que gostam das aulas de EFE. Este fato está em concordância com Silva et al. (1996) que dizem que o gosto dos alunos pela EFE está intimamente relacionada com sua satisfação pela prática de AF, sem maiores preocupações com possíveis conhecimentos a serem transmitidos.

Somente um aluno (13) declarou que não gosta das aulas de EFE. Disse que não gosta das aulas de EFE porque não gosta de esportes, concordando com Conceição et al. (2004a), que afirmam que há alguns alunos que não gostam de esporte. Neste sentido, Canfield et al. (1995), dizem que o gosto dos alunos pela EFE tem que ser um dos objetivos do professor. Destacam ainda que o professor que consegue motivar seus alunos torna o conteúdo trabalhado significativo, elabora objetivos adequados e, quem sabe, conta com a participação destes.

O motivo que leva ao gosto pelas aulas de EFE, de acordo com quatorze alunos (2; 3; $4 ; 5 ; 8 ; 10 ; 12 ; 14 ; 15 ; 16 ; 17 ; 18 ; 19 ; 20)$, é gostar de esporte. Marchesan et al. (2007) também verificaram resultados parecidos, onde $81 \%$ dos alunos gostavam da EFE por causa dos esportes. Quatro alunos $(1 ; 6 ; 7 ; 9)$ manifestaram que gostam porque é bom para a saúde. Este fato coincide com os encontrados por Ilha et al. (2006), em que a maioria dos alunos do ensino médio destacaram a importância da EF em relação a saúde. Da mesma forma, Guedes e Guedes (1994) defendem uma EFE voltada para a saúde, onde os conteúdos precisam deixar a superficialidade das atividades práticas e se aprofundarem numa base de conhecimentos que oferecerão aos alunos o acesso às informações e ao domínio dos conceitos, influenciando em uma tomada de decisões para a aquisição de um estilo de vida ativo. 


\section{A participação dos alunos nas aulas de EFE.}

Quinze alunos $(1 ; 2 ; 3 ; 5 ; 6 ; 8 ; 9 ; 10 ; 11 ; 12 ; 16 ; 17 ; 18 ; 19 ; 20)$ declararam que participam regularmente das aulas de EFE. Segundo Darido et al. (1999) os alunos já na adolescência costumam participar das aulas de EFE baseados em suas experiências anteriores, sendo assim, se estas foram marcadas por sucesso e prazer, terão uma opinião favorável quanto a frequentar as aulas, mas se forem marcadas por situações de insucesso, ou de exclusão, sua opção será pela não frequência, com o discurso pautado em não gostar desta disciplina.

Já Darido e Rangel (2005) explicam que todos os alunos têm direto, enquanto cidadãos, de participar das aulas de EF, independentemente da cor, etnia, religião, gênero, idade etc., o problema do professor reside em encontrar alternativas para a não exclusão repensando sua própria prática pedagógica, a fim de torná-la acessível a todos os alunos.

Cinco alunos $(4 ; 7 ; 13 ; 14 ; 15)$ declararam não participar regularmente das aulas de EFE. Esta situação é ressaltada por Ilha et al. (2006) que afirmam que, nos últimos anos, a EF vem apresentando dificuldades em cativar os alunos para participarem das aulas. Já Rosa e Krug (2009) destacam que no ensino médio os alunos pouco se envolvem com a EF e alguns chegam a não frequentar as aulas.

Com relação aos motivos dos quinze alunos para a sua participação nas aulas de EFE, onze $(2 ; 3 ; 6 ; 8 ; 9 ; 11 ; 12 ; 16 ; 17 ; 18 ; 19)$ declararam que foi pela prática de esportes. Paz e Pires (2002) salientam que a prática de esportes nas aulas é uma constante e ocupa uma posição importante na preferência dos alunos e nos conteúdos mais trabalhados pelos professores. Quatro alunos $(1 ; 5 ; 10 ; 20)$ declararam que foi a obrigatoriedade em frequentar esta disciplina, fato que nos preocupa, pois Silva et al. (1996) explicam que, os alunos compreendem os benefícios da EFE quando não vinculam sua participação à obrigatoriedade.

Em relação aos motivos dos cinco alunos que não participam das aulas de EFE, quatro $(4 ; 7 ; 14 ; 15)$ declararam que foi pela apresentação do atestado médico. De acordo com Ilha et al. (2006), apesar da obrigatoriedade da EF em todos os níveis de ensino, ao longo de sua história, foram abertas algumas exceções que acabaram por influenciar esta disciplina na escola. Segundo o art. 26, $3^{\circ} \S$, da Lei n. 9.394/96 (BRASIL, 1996) é facultativa a prática da EF em todos os graus de ensino, ao aluno que comprove trabalhar pelo menos 6 horas diárias com carteira assinada, com atestados de trabalho reconhecido em cartório, aos alunos doentes, mediante laudo médico e a aluna que tenha prole. No entanto, esse amparo legal existe apenas 
para a dispensa das aulas de EF, como expressa o Coletivo de Autores (1992, p.42): “Por acaso alguma lei dispensa das aulas de História, Geografia (...)?. Certamente não”. Um único aluno (13) declarou não participar das aulas de EFE por não gostar de praticar esportes.

\section{Como eram as aulas de EFE na escola}

Para todos os alunos as aulas de EFE durante as 'Séries Iniciais do Ensino Fundamental' foram exclusivamente recreativas. Existem 3 tendências da EFE nas séries inicias do ensino fundamental: a psicomotricidade, o desenvolvimento/aprendizagem motora, e a recreação. A recreação foi apropriada pela EF como modelo de lazer ou de EF informal, aquela que acontece fora do âmbito escolar. Inicialmente, ela foi utilizada como conteúdo e método para o desenvolvimento das aulas de EF nas séries iniciais do ensino fundamental e posteriormente, com iniciativas de implementação de profissionais de EF nestas séries, havendo uma transposição das práticas propostas nas séries iniciais para a educação infantil (GEAEF, 1996).

Todos os alunos declararam que as aulas de EFE durante as 'Séries Finais do Ensino Fundamental' foram exclusivamente iniciação esportiva ou somente jogo de alguns esportes. Estas informações vão ao encontro dos dados de Darido e Rangel (2005) onde as atividades na EFE estão restritas e diretamente vinculadas aos esportes, fortalecendo o aprendizado de habilidades técnicas esportivas e o jogo em si.

Quanto ao esporte mais praticado, 19 alunos $(1 ; 2 ; 3 ; 4 ; 5 ; 6 ; 7 ; 8 ; 9 ; 10 ; 11 ; 12 ; 14$; $15 ; 16 ; 17 ; 18 ; 19 ; 20)$ disseram o futsal, seguido do voleibol (15 alunos) $(1 ; 2 ; 3 ; 4 ; 7 ; 8 ; 9$; $10 ; 11 ; 12 ; 14 ; 15 ; 16 ; 17 ; 20)$, do handebol (12 alunos) $(2 ; 3 ; 4 ; 7 ; 8 ; 10 ; 12 ; 14 ; 15 ; 17$; 20) e do basquetebol (9 alunos) $(1 ; 2 ; 3 ; 4 ; 10 ; 14 ; 16 ; 17 ; 20)$. Mendonça (2002) explica que os esportes mais praticados nas aulas de EFE são o futsal e o voleibol, esportes muito divulgados pela mídia (programas de televisão, rádios e jornais) estimulando assim o interesse dos alunos em praticá-los e dos professores em desenvolvê-los. Já Darido e Rangel (2005) acrescentam que o basquetebol e o handebol são praticados em menor escala nas aulas de EF se comparados ao futsal e ao voleibol. Cinco alunos $(2 ; 4 ; 9 ; 10 ; 14)$ relataram que o atletismo foi o esporte mais praticado e um aluno (10) citou a ginástica olímpica. Darido e Rangel (2005) dizem que na escola as modalidades esportivas individuais tem encontrado pouco espaço, o que, de certa forma, representa uma limitação à aprendizagem dos alunos, pois eles auxiliam, dentre outras coisas, na descoberta do próprio corpo. 
Todos os participantes disseram que as aulas de EFE durante o Ensino Médio foram exclusivamente a prática de jogos esportivos. Estas informações concordam com Krug e Krüger (2007) de que no ensino médio as aulas de EF abordam basicamente os esportes coletivos.

Dezessete alunos $(1 ; 2 ; 3 ; 4 ; 5 ; 6 ; 7 ; 8 ; 9 ; 11 ; 12 ; 13 ; 14 ; 16 ; 17 ; 18 ; 19 ; 20)$ mencionaram que as aulas estavam organizadas em forma de clubes. Conceição et al. (2004b) ressaltam que a denominação clubes para as aulas de EFE enfatiza a aprendizagem de apenas uma modalidade esportiva.

Já os esportes coletivos mais trabalhados no Ensino Médio foram o futsal $(1 ; 3 ; 4 ; 6$; $7 ; 10 ; 14 ; 15 ; 17 ; 18 ; 19 ; 20)$, voleibol $(1 ; 2 ; 3 ; 4 ; 8 ; 9 ; 10 ; 12 ; 15 ; 16 ; 17)$, basquetebol $(5 ; 10 ; 15 ; 17)$ e handebol $(10 ; 11 ; 17)$. O estudo de Rech et al. $(2001)$ constatou que os esportes coletivos mais difundidos nas escolas são o futsal, o voleibol, o basquetebol e o handebol.

Mediante este quadro descrito das aulas de EFE podemos perceber que estas aulas de EF estão restritas aos esportes coletivos, que são os que mais despertam interesse na população (DARIDO; RANGEL, 2005). Essa influência do esporte na escola é tão grande que temos, então, não o esporte da escola, mas sim o esporte na escola, indicando a subordinação da EF aos códigos da instituição esportiva, identidade essa fortalecida pela pedagogia tecnicista (COLETIVO DE AUTORES, 1992).

\section{A participação dos alunos em equipes escolares}

Treze alunos $(1 ; 3 ; 4 ; 5 ; 7 ; 9 ; 10 ; 11 ; 14 ; 17 ; 18 ; 19 ; 20)$ disseram que participaram de equipes competitivas na escola. Em estudo realizado por Krug et al. (2009a) resultados parecidos foram encontrados, pois muitos alunos também já haviam participado de equipes escolares. Neste estudo as mais citadas foram: Futsal $(1 ; 3 ; 4 ; 5 ; 7 ; 14 ; 17 ; 18 ; 19 ; 20)$, Voleibol (1; 17), Hanbebol (9; 11) e Basquetebol (10). De acordo com Daronco et al.(2002) as equipes escolares, que representam à escola em jogos, são vistas por algumas escolas como o único objetivo da EFE. Canfield (1998) diz que a aula de EF não pode ser confundida com um grupo de lazer, um clube, um lugar de treinamento preparatório para competições, sendo sim, um lugar de obrigações, confrontações e diferenças.

É importante destacar que sete alunos $(2 ; 6 ; 8 ; 12 ; 13 ; 15 ; 16)$ não participaram de equipes. Podemos inferir que estes alunos talvez não tiveram essa oportunidade, devido há 
alguns motivos alheios as suas vontades, como não ter equipes na escola, não ser convidado pelo professor, não possuir habilidades esportivas mais apuradas, pois vários deles disseram que gostam de esportes $(2 ; 8 ; 12 ; 15 ; 16)$.

\section{A opinião dos alunos sobre a importância da EF no currículo escolar.}

Dezenove alunos $(1 ; 2 ; 3 ; 4 ; 5 ; 6 ; 7 ; 8 ; 9 ; 10 ; 11 ; 12 ; 14 ; 15 ; 16 ; 17 ; 18 ; 19 ; 20)$ depuseram que a EF é uma disciplina importante no currículo escolar. Este fato é corroborado por Barros (1992) que afirma que esta vem sendo reconhecida por muitos estudiosos como uma disciplina com relevância educacional. Já Mariz de Oliveira (2000) diz que, a EF independente da legislação, deve ser um componente curricular único, específico e integrado à proposta pedagógica de todas as modalidades de educação e ensino. Para Oliveira (1992) não há dúvida quanto à importância da EF na escola. Contudo o autor ressalta que estamos prestes a perder este espaço caso continuemos com práticas descompromissadas com a transmissão e produção do conhecimento.

Somente 1 aluno (13) depôs que a EF não é importante no currículo escolar. Esta opinião pode ser respaldada com a colocação de Silva et al. (1996) de que na escola é dada maior importância às disciplinas socialmente valorizadas, de base profissional, atribuindo assim pouca importância formativa às disciplinas de cunho humanístico.

\section{O incentivo do professor de EFE para a prática de AF fora da escola.}

Dez alunos $(1 ; 3 ; 5 ; 7 ; 8 ; 10 ; 12 ; 14 ; 15 ; 17)$ salientaram que o professor de EFE os incentivava a praticar AF fora da escola. Hurtado (1983) enfatiza que o professor influencia o aluno, tanto pelo que ensina como pelo que faz, pelo bom exemplo que dá. Diante dessa concepção, o professor de EF desponta como mediador da prática de AF, tendo importante papel em relação à promoção a saúde, educação e prevenção de doenças, contribuindo assim para hábitos de vida mais saudáveis (KRUG et al., 2009b).

Os demais alunos $(2 ; 4 ; 6 ; 9 ; 11 ; 13 ; 16 ; 18 ; 19 ; 20)$ informaram que o professor de EFE não os incentivava a praticar AF fora da escola. Canfield (1998) relata que o professor de EFE precisa saber quem é o seu aluno, do que ele precisa, de seus limites e desejos, para que o seu fazer pedagógico seja revestido de importância em uma necessidade continuada por toda sua vida. A autora destaca que o professor de EF precisa colocar significado em sua aula, pois 
só assim, os alunos adotarão o hábito da prática regular de AF em suas vidas.

Com relação ao incentivo do professor de EFE nas AF fora da escola, os alunos $(1 ; 3$; $5 ; 7 ; 8 ; 10 ; 12 ; 14 ; 15 ; 17)$ explicam que foi com conversas sobre os benefícios da AF. Canfield (1998) salienta que se os professores gostarem do que fazem e conhecerem o que fazem, possivelmente as pessoas acreditarão nas mensagens da importância da prática de AF que forem passadas nas aulas, vindo a assumirem um estilo de vida ativo, desta forma, o fazer pedagógico irá além dos muros da escola, e acompanhará as pessoas durante toda vida.

\section{A prática da EF fora da escola.}

\section{A participação dos alunos em AF fora da escola.}

Dezessete alunos $(1 ; 2 ; 3 ; 4 ; 5 ; 6 ; 7 ; 8 ; 9 ; 10 ; 11 ; 12 ; 15 ; 17 ; 18 ; 19 ; 20)$ afirmaram realizar AF fora da escola, sendo o futsal mais citado $(1 ; 3 ; 4 ; 5 ; 6 ; 7 ; 8 ; 16 ; 17 ; 18 ; 19 ; 20)$. Daronco et al. (2002) enfatizam que o futsal está em notório desenvolvimento no Brasil. A musculação é a segunda AF mais praticada $(1 ; 2 ; 3 ; 5 ; 6 ; 7 ; 8 ; 9 ; 10)$ e, segundo Krug et al. (2006), a cada ano que passa a musculação vem se difundindo cada vez mais entre a população em geral. Também citaram a dança $(4 ; 11)$ e a corrida de rua (2).

O motivo que leva quatro alunos a participarem de AF fora da escola foi para melhorar a estética $(6 ; 7 ; 8 ; 9)$. Este fato corrobora com Zanatta e Fonseca (2008) quando dizem que a aparência corporal tem recebido grande destaque e valorização na sociedade, influenciando as pessoas a praticar AF. Sete alunos $(1 ; 3 ; 16 ; 17 ; 18 ; 19 ; 20)$ declararam ter sido o gosto pelo futebol, um aluno (4), o gosto pela dança, outro (12) o gosto pela corrida, e ainda outro (10) declarou que foi para estar com os amigos. Miranda e Batista (1999) afirmam que o prazer é fundamental para a aderência à AF.

\section{Os alunos estudados possuem um estilo de vida ativo?}

\begin{tabular}{|c|l|c|c|}
\hline Aluno & \multicolumn{1}{|c|}{ Atividade praticada } & $\begin{array}{c}\text { Horas/ } \\
\text { semana }\end{array}$ & $\begin{array}{c}\text { Recomendação de } \\
\text { Hallal et al. (2003) }\end{array}$ \\
\hline 1 & Futsal (6 x 1h) e Musculação (5 x 1h) & $11 \mathrm{~h}$ & SIM \\
\hline 2 & Musculação (5 x 1h30m) & $7 \mathrm{~h} 30 \mathrm{~m}$ & SIM \\
\hline 3 & Musculação (6 x 1h) e Futsal (6 x 1h) & $12 \mathrm{~h}$ & SIM \\
\hline
\end{tabular}




\begin{tabular}{|c|c|c|c|}
\hline 4 & Dança (2 x 1h) e Futsal (1 x 1h) & $3 h$ & $\mathrm{NA} \mathrm{A} * *$ \\
\hline 5 & Musculação (5 x 1h30m) e Futsal (1 x 1h) & $8 \mathrm{~h} 30 \mathrm{~m}$ & SIM \\
\hline 6 & Musculação (3 x 1h) e Futsal (1 x 1h) & $4 \mathrm{~h}$ & NÃO* \\
\hline 7 & Musculação (5 x 1h) e Futsal (3 x 1h) & $8 h$ & SIM \\
\hline 8 & Musculação (5 x 1h) e Futsal (1 x 1h) & $6 \mathrm{~h}$ & SIM \\
\hline 9 & Musculação (5 x 1h) & $5 \mathrm{~h}$ & SIM \\
\hline 10 & Musculação (5 x 1h) & $5 h$ & SIM \\
\hline 11 & Dança (2 x 1h) & $2 \mathrm{~h}$ & NÃO \\
\hline 12 & Corrida de rua ( 7 x 3h) & $21 \mathrm{~h}$ & SIM \\
\hline 13 & Nenhuma & 0 & NÃO \\
\hline 14 & Nenhuma & 0 & NÃO \\
\hline 15 & Nenhuma & 0 & NÃO \\
\hline 16 & Futsal (3 x 2h) & $6 \mathrm{~h}$ & SIM \\
\hline 17 & Futsal ( 2 x 1h) & $2 \mathrm{~h}$ & NÃO \\
\hline 18 & Futsal (4 x 1h) & $4 \mathrm{~h}$ & NÃO* \\
\hline 19 & Futsal (3 x 1h) & $3 h$ & NÃO** \\
\hline 20 & Futsal (3 x 1h) & $3 h$ & NÃO** \\
\hline
\end{tabular}

Quadro 1. Relação das Atividades Físicas semanais praticadas pelos alunos x a recomendação de Hallal et al. (2003) de 300 minutos semanais de Atividades Físicas.

No Quadro 1 constatamos que 10 alunos $(1 ; 2 ; 3 ; 5 ; 7 ; 8 ; 9 ; 10 ; 12 ; 16)$ estudados atingem a recomendação de 300 minutos semanais de AF regulares citada por Hallal et al. (2003). Pode-se perceber também que 2 alunos* $(6 ; 18)$ realizam 4 horas semanais de AF fora do período escolar e que 3 alunos** $(4 ; 19 ; 20)$ praticam 3 horas semanais, e que se eles têm 3 períodos de 50 minutos de EFE em forma de clubes, ou seja, praticando algum esporte, pode-se somar mais duas horas e 30 minutos de AF semanais para estes alunos, o que ultrapassaria a recomendação mínima de 300 minutos semanais.

\section{As contribuições da EFE para um estilo de vida ativo.}

A frequência dos alunos nas aulas de EFE, na opinião deles, estaria contribuindo para um estilo de vida ativo pelas seguintes ações: a- Saúde $(2 ; 3 ; 5 ; 6 ; 7 ; 8 ; 10 ; 11 ; 14 ; 15 ; 16$; $18 ; 19 ; 20)$ e condicionamento físico $(1 ; 3 ; 6 ; 12 ; 14)$. Estas duas ocorrências vão ao encontro do trabalho de Schmidt e Krug (2004), onde os alunos fizeram 6 meses de um programa de EF curricular, com ganhos em alguns aspectos do condicionamento físico e da saúde; b- Bem 
estar $(2 ; 10)$. Nahas (2006) coloca que pessoas que têm um estilo de vida mais ativo tendem a ter uma autoestima maior e uma percepção de bem-estar psicológico positivo; c- Iniciação para a prática de esportes $(15 ; 18)$. Daronco et al. (2002) afirmam que os esportes vêm sendo trabalhados nas escolas sob a forma de especialização, onde o aluno normalmente pratica durante toda a EFE apenas uma modalidade esportiva e desta forma melhora a sua performance; d- Estética (8) e; e- Nenhuma contribuição (13).

Neste estudo, evidenciou-se, na opinião dos alunos pesquisados, que a EFE está contribuindo para a saúde, porém Hallal et al. (2003) e WHO (2002) explicam que a saúde de um individuo é influenciada não somente pela prática regular de AF, mas também por uma boa alimentação e por boas condições de moradia e de saneamento básico.

\section{Conclusão}

O presente estudo demonstrou que EFE contribuiu para um estilo de vida ativo, melhorando a saúde, o condicionamento físico, o bem-estar, a prática de esportes e a estética.

Outro dado que chama atenção é a forte influência do esporte nas AF desenvolvidas tanto na escola quanto fora dela, sendo que esse gosto por ele foi o principal motivo de participação dos alunos das aulas de EFE e das equipes escolares, bem como na participação das AF fora da escola.

Dos vinte alunos entrevistado, quinze possuem um estilo de vida ativo, dois praticam pouco tempo de AF e três são inativos. Os alunos que não praticam AF fora da escola também não participam das aulas de EFE. Assim, pode-se evidenciar que as aulas não os influenciam uma vez que eles não as frequentam.

As AF mais praticadas pelos alunos fora da escola são o futsal e a musculação que são muito abordadas pela mídia. No entanto, o interesse dos alunos em determinada modalidade esportiva pode ser muito influenciada pela mídia, mas a sua permanência nesta modalidade se dará pelo prazer, benefícios etc. Portanto, a mídia também pode ser um elemento auxiliador na escolha por um estilo de vida ativo.

Nesse sentido, o papel do professor de EFE deve ser estimular e incentivar os alunos a serem mais ativos, tornando as aulas mais agradáveis e atrativas, colaborando assim com a saúde e qualidade de vida não somente durante a vida escolar, mas sim na vida futura. 


\section{Referências}

BARDIN, L. Tradução de Luis Antero Neto e Augusto Pinheiro. Análise de conteúdo. Lisboa: Edições 70, 1977.

BARROS, J.M.C. Educação Física: conteúdos e programas. Revista Kinesis, Santa Maria, n.9, p.97-110, 1992.

BRASIL. Lei n. 9.394. Lei de Diretrizes e Bases da Educação Nacional. Brasília: Congresso Nacional, 1996.

CANFIELD, M.S. Educação Física: necessidades educativas do futuro. Revista Kinesis, Santa Maria, n.20, p.129-137, 1998.

CANFIELD, M.S. et al.Os alunos gostam das aulas de Educação Física? In: PEREIRA, F.M. (Org.). Educação Física: textos do XV Simpósio Nacional de Ginástica. Pelotas: ESEF/UFPEL, 1995. p.75-86.

COLETIVO DE AUTORES. Metodologia do ensino da Educação Física. São Paulo: Cortez, 1992.

CONCEIÇÃO, V.J.S. et al. A estruturação organizacional da Educação Física no ensino fundamental em Santa Maria-RS. In: SIMPÓSIO NACIONAL DE EDUCAÇÃO FÍSICA, XXIII, 2004, Pelotas. Anais, Pelotas: ESEF/UFPEL, 2004b. CD-ROM.

CONCEIÇÃO, V.J.S. et al. A opinião discente sobre a Educação Física no ensino fundamental em Santa Maria-RS. In SIMPÓSIO NACIONAL DE EDUCAÇÃO FÍSICA, XXIII, 2004, Pelotas. Anais, Pelotas: ESEF/UFPEL, 2004a. CD-ROM.

DAÓLIO, J. Educação Física Escolar: Em busca da pluralidade. Revista Paulista de Educação Física, supl. 2, p. 40-42, 1996.

DARIDO, S.C. et al. Educação Física no ensino médio: reflexões e ações. Revista Motriz, v.5, n.2, p.139-141, 1999.

DARIDO, S.C.; RANGEL, I.C.A. Educação Física na escola: implicações para a prática pedagógica. Rio de Janeiro: Guanabara Koogan, 2005.

DARONCO, A. et al. Estudo da aptidão motora de atletas de equipes escolares e alunos de Educação Física regular das escolas de Santa Maria-RS. Revista Kinesis, Santa Maria, p.135148, 2002.

DEVIDE, F. P. Educação Física e Saúde: Em busca de uma reorientação para sua práxis. Revista Movimento. Porto Alegre: ano III, n. 5, p. 44-55, 1996.

FERREIRA, M.S. Aptidão física e saúde na Educação Física Escolar: Revista Brasileira de Ciências do Esporte, v.22, n.2, p.41-54, jan., 2001.

GOODE, L.; HATT, K. Métodos em pesquisa social. São Paulo: Cia. Editora Nacional, 1968. 
GRUPO DE ESTUDOS AMPLIADOS DE EDUCAÇÃO FÍSICA. Diretrizes curriculares para a Educação Física no ensino fundamental e na educação infantil da rede municipal de Florianópolis-SC. Florianópolis: NEDEF/UFSC-SME/ Florianópolis, 1996.

GUEDES, D.P.; GUEDES, J.E.R. A influência da prática da atividade física em crianças e adolescentes: uma abordagem morfológica funcional. Revista da Associação dos Professores de Educação Física de Londrina, Londrina, v.10, n.17, p.3-25, 1995.

Sugestões de conteúdos programáticos para programas de Educação Física Escolar direcionados à promoção da saúde. Revista da Associação dos Professores de Educação Física de Londrina, Londrina, v.9, n.16, p.3-14, 1994

HALLAL, P.C. et al. Adolescent physical activity and health: a systematic review. Sports Medicine, v.36, n.12, p.1019-1030, 2003.

HURTADO, J.G.G.M. O ensino da Educação Física: uma abordagem didática. 2. ed. Curitiba: Educa/Editer, 1983.

ILHA, F.R. et al. A evasão dos alunos do ensino médio nas aulas de Educação Física. Revista Biomotriz, Cruz Alta, n.4, p.15-31, nov., 2006.

Joint WHO/FAO. Expert consultation on diet, nutrition and the prevention of chronic diseases. Geneva, Switzerland, 2002.

KOOGAN, L.; LAROUSSE, P. Pequeno dicionário enciclopédico. Rio de Janeiro: Larousse, 1990.

KRUG, R.R. et al. Perfil dos profissionais de Educação Física que atuam em academias de musculação na região central da cidade de Criciúma-SC. Boletim Brasileiro de Educação Física, Brasília, v.73, p.1-9, 2009b.

KRUG, R.R. et al. As lembranças significativas do tempo de educação física escolar na educação básica pelos licenciandos do CEFD/UFSM: colaborando com o "aprender a ser professor". Boletim Brasileiro de Educação Física (Brasília), v. 10, p. 1-9, 2009a.

KRUG, R.R et al. Os benefícios da prática da musculação para os frequentadores da Academia Oficina do Corpo e da Menta de Cruz Alta-RS: um estudo de caso. In: JORNADA NACIONAL DE ATIVIDADES FÍSICAS, VI, 2006, Cachoeira do Sul. Manual de Resumos, Cachoeira do Sul: ULBRA, 2006. p.10.

KRUG, H.N.; KRÜGER, L.G. A estruturação organizacional da Educação Física no ensino médio em Santa Maria-RS nas escolas com Estágio Curricular Supervisionado do CEFD/UFSM. In: SIMPÓSIO NACIONAL DE EDUCAÇÃO FÍSICA, XXVI, 2007, Pelotas. Anais, Pelotas: Escola Superior de Educação Física/Universidade Federal de Pelotas, 2007. CD-ROM.

MARCHESAN, M. et al.Preferências e desgostos de alunos da $5^{\mathrm{a}}$ série do ensino fundamental de alunos da Escola Municipal de Ensino Fundamental Carlos Gomes da cidade de Cruz AltaRS. In: SEMINÁRIO INTERNACIONAL DE EDUCAÇÃO NO MERCOSUL, XI, 2007, 
Cruz Alta. Anais. Cruz Alta: UNICRUZ, 2007. v.1.

MARIZ DE OLIVEIRA, J.G. Educação Física no ensino fundamental: a percepção de alunas e alunos referente a alguns aspectos de suas aulas na sétima e oitava séries. Caderno de Educação Física: estudos e reflexões, Marechal Cândido Rondon, v.1, n.2, p.25-40, 2000.

MENDONÇA, R.S. O jogo e o processo educativo nas aulas de Educação Física. Uma análise da rede municipal de ensino de Santa Maria. Revista Kinesis, Santa Maria, n.26, p.65-77, 2002.

MIRANDA, C.J.M.; BATISTA, L.A. O prazer como determinante da aderência à atividade física por adolescentes, o caso do contexto escolar. In: CONGRESSO DE EDUCAÇÃO FÍSICA E CIÊNCIAS DO ESPORTE DOS PAÍSES DE LÍNGUA PORTUGUESA, XVII, 1999, Florianópolis. Livro de Resumos, Florianópolis, 1999. p.461.

NAHAS, M.V. Atividade física, saúde e qualidade de vida. 4. ed. Londrina: Midiograf, 2006.

OLIVEIRA, A.A.B. Analisando a prática pedagógica da Educação Física. Revista da Associação dos Professores de Educação Física de Londrina, Londrina, v.VII, n.13, p.11-14, jul., 1992.

ORGANIZAÇÂO PAN-AMERICANA DE SAÚDE. Doenças crônico-degenerativas e obesidade: estratégia mundial sobre alimentação saudável, atividade física e saúde. OPAS. Brasília, 2003.

PAZ, J. R. L.; PIRES, V. Visão do aluno sobre a Educação Física na escola: um estudo com a $8^{\text {a }}$ série de ensino fundamental de Santa Cruz-RS: In: SIMPÓSIO NACIONAL DE EDUCAÇÃO FÍSICA, XXI, 2002, Pelotas. Anais, Pelotas: ESEF/UFPEL, 2002. 100- 111. CD-ROM.

QUADROS, C. T.; KREBS, R. J. Aptidão física voltada à promoção da saúde em escolares do município de Santiago-RS. Revista Kinesis, Santa Maria, v.2, n.3, 1998.

RECH, C. R. et al. Comparação entre os níveis de aptidão motora de alunos participantes de equipes escolares em diferentes modalidades esportivas na cidade de Santa Maria (RS). In: CONGRESSO MERCOSUL DE CULTURA CORPORAL E QUALIDADE DE VIDA, I, 2001, Ijuí. Anais, Ijuí: UNIJUÍ, 2001. p. 66-67.

ROSA, V.T.; KRUG, H. N. A Educação Física organizada em forma de clubes no ensino médio e seus procedimentos metodológicos, 2009. Monografia (Especialização em Educação Física Escolar) - Universidade Federal de Santa Maria, Santa Maria, 2009.

SCHMIDT, R.; KRUG, M.R. Frequência das aulas de Educação Física e sua contribuição para o desenvolvimento da aptidão física. Revista Biomotriz, Cruz Alta, n.2, p.127, nov., 2004.

SILVA, O.G.T. et al. Perfil das preferências culturais e desportivas dos alunos do Colégio Pedro II. Revista Artus, Rio de Janeiro, v.12, n.1, p.45-59, 1996.

TRIVIÑOS, A.N.S. Introdução à pesquisa em ciências sociais - pesquisa qualitativa em 
educação. São Paulo: Atlas, 1987.

ZANATTA, A.G.; FONSECA, P.H.S. Prevalência de indivíduos com sintomas de dependência ao exercício no ambiente de academia de ginástica. Caderno de Educação Física: estudos e reflexões, Marechal Cândido Rondon, v.7, n.13, p.33-43, 2008. 